Ruth Ann Strickland and Marcia Lynn Whicker. 1992. "Political and Socioeconomic Indicators of State

Restrictiveness Toward Abortion." Policy Studies Journal 20 (Winter, no.4): 598-617. (ISSN: 0190-292X) DOI:

10.1111/1541-0072.ep11570637 Publisher: Wiley-Blackwell [The definitive version is available at

www3.interscience.wiley.com]

\title{
Political and Socioeconomic Indicators of State Restrictiveness Toward Abortion
}

\author{
Ruth Ann Strickland and Marcia Lynn Whicker.
}

\begin{abstract}
We compare the relative impacts of political and socioeconomic factors on state restrictiveness toward abortion during the pre. Roe, pre-Webster and post-Webster time frames. This analysis tests the value of cycle theory, where shifting epochs dominated by liberalism and conservatism enhance the role of political variables in shaping policy formation. It also tests the explanatory value of public opinion theory which holds that bimodal issues which cut across party lines accentuate the role of socioeconomic variables in shaping issue evolution. The results of this analysis lend support to cycle theory and public opinion theory, although public opinion theory receives stronger support. When socioeconomic independent variables are regressed against our dichotomous measures of state restrictiveness toward abortion, they explain more variance than political independent variables. Political variables were more important in the conservative era (1989) than in the liberal era (1972).
\end{abstract}

\section{ARTICLE}

\section{Historical Cycles in Political Agendas}

Schlesinger (1986) has argued that public focus shifts from liberalism to conservatism in roughly 30-year cyclical intervals, driven in part by leadership transitions, marking a "changing of the guard." Underlying the leadership transitions are demographic shifts that also reflect aging of the population. At each cusp, a new generation comes to power, greatly influenced by its socialization roughly 30 years previously. The beginning of each new period is often accompanied by shifts in partisanship and loyalties.

During liberal eras, redistribution and social programs that expand the power of the underclass and disadvantaged achieve greater prominence. Partisan and political factors play a dominant 
role in agenda creation, since party politics become a major mechanism for mobilizing the less advantaged and for implementing new social programs that redistribute the wealth and empower the weak. During conservative eras, allegiances to social class am also manifested through party politics, only the party promoting the interests of the upper rather than the disadvantaged classes holds power (Philips, 1990).

The 1960s represented a shift from the conservatism of the 1950s to a more liberal period. Political agendas were largely shaped by people socialized in the 1930s depression era, who remembered hardship and emphasized redistribution and social programs. By the 1980s, the tide had shifted to an era of conservatism, with leadership positions dominated by people socialized in the more conservative 1950s. In each instance, these class differences, according to cycle theory, were manifested through partisan loyalties and leadership.

This article examines factors affecting one crucial public issue--that of abortion--for the pre-Roe v. Wade era (1972) and the post-Roe era (including pre-Webster and post-Webster time periods). Abortion policy in 1972 was shaped in part by the cumulative political and socioeconomic forces in the 1960s and therefore reflects a more liberal era. During the pre-Webster period, states had less flexibility in determining abortion outcomes as state policies were constrained by the U.S. Supreme Court ruling in Roe. Abortion policy in the post-Roe period was influenced by the cumulative political and socioeconomic factors in the 1980s as well as the Webster decision itself and therefore reflects a more conservative era.

If the cycle theory of history is relevant to policy formation concerning abortion, political and partisan factors should be dominant. A valid empirical test of cycle theory would require at least two periods for analysis, one during a liberal era and one during a conservative era. In addition to 1972 and 1989 representing watershed time periods in judicial interpretation of abortion rights, these two periods also represent liberal and conservative eras, which are needed to test cycle theory empirically.

\section{The Bimodal Characteristics of Abortion}

An alternative explanation of issue evolution for abortion is the theory surrounding the shape of public opinion. Under public opinion theory, issues where public opinion is unimodal promote moderate positions and consensus, while issues where public attitudes are bimodal are more controversial and conflict laden. Party politics, negotiation, and compromise characterize unimodal issues, whereas bimodal issues cut across party lines and reflect basic socioeconomic, class, and religious differences (Downs, 1957; Dawson, 1973). This result is a function of the interaction between the shape of public opinion and a single-member district majority-rule system of representation. Under such a representation system, any winning candidate or party must capture a majority of the votes to attain office. When opinion is unimodal and centrist, candidates must assume moderate positions to win the votes of a majority of voters who are largely moderate and mainstream. When opinion is bimodal, however, candidates are driven toward one of the two modes on the extremes, and public debate is more acrimonious. 
Common ground between pro-life and pro-choice advocates has been difficult to achieve because the debate surrounding abortion rights is often framed in bimodal terms, with opponents assuming intensely held, mutually exclusive positions (Tedrow \& Mahoney, 1979). Illustrative of the nonoverlapping positions drawn by opponents is the fundamental dispute over when life begins: either life begins at conception or not, and thus, either the fetus is a person to be protected or not.

In the debate over abortion, moral overtones and righteous actions and reactions are common, adding intensity and further diminishing the probability of political compromise (Strickland \& Whicker, 1986, pp. 46-47; Callahan, 1986, p. 204; Granberg, 1981b, p. 35; Fried, 1988, p. 152). The conflict over abortion is further intensified by the fact that access to abortions gives women increased control over their bodies and alters the power balance between the sexes (Whicker \& Kronenfeld, 1986). Various studies have linked attitudes toward abortion to the demographic characteristics of individuals who seek abortions (Henshaw, Binkin, Blaine, \& Smith, 1985; Henshaw, Forrest, Sullivan, \& Tietze, 1981; Henshaw \& O'Reilly, 1983; Sullivan, Tietze, \& Dryfoos, 1977; Tietze, 1977; Burnham, 1983; Prager, 1985). Thus, if public opinion theory which focuses on the interaction between the shape of public opinion distributions and the representative system provides greater explanatory value for abortion policy development, then socioeconomic factors should dominate policy formation and outcomes in both time periods-pre-Roe and post-Roe (Petchsky, 1990).

\section{The Impact of Religion on the Issue of Abortion}

One major socioeconomic factor likely to affect abortion policy is religion. A number of studies indicate that stances on abortion are affected by religious affiliation (Hertel \& Hughes, 1987, p. 877). Other studies, which rely on survey data and more directly measure individual intensity of opinion, find that abortion attitudes are not necessarily a function of religious preference but are a function of intensity of religious preference (Baker, Epstein, \& Forth, 1981). Intensity of religious preference is a more appropriate variable for individuals than for states--the primary unit of analysis here. To compile a state level measure of intensity of religion would require treating individual survey responses to scale-questions probing intensity as interval for the purpose of aggregation, a questionable treatment of ordinal data.

The nation's churches are profoundly split on the issue (Meehan, 1981, p. 650; Granberg, 1981a, p.160). The Roman Catholic, the Mormon, the Southern Baptist, and Lutheran church policies are firmly opposed to abortion, as are Assemblies of God and other fundamentalist churches. Other religious denominations have moderated their positions on abortion, but are still opposed to its use under many circumstances. American Baptists have shifted from the position that abortion is a matter of personal choice to opposition to abortion as a means of birth control. The United Methodists have also accepted abortion but in recent years opposed it as a means of gender selection or as a method of birth control (Woodward \& Cohen, 1989, pp. 45-46). 


\section{Partisan Positions on Abortion}

If cycle theory provides a useful explanation for evolving abortion policy, political factors should influence policy formation during both liberal and conservative eras. There are indications that partisan politics will shape future abortion policy.

\section{State Party Politics and Abortion}

As a result of the Supreme Court's ruling in the Webster case, both political parties geared up in 1989 for abortion battles in gubernatorial and state legislative races in the 1990s. Since governors and state legislators had previously been shielded from serious public scrutiny and public accountability on abortion by Roe v. Wade, the recent change in the status quo promised to draw and/or force state politicians out into the open again on this most sensitive issue (Edsall, 1989, p. 10).

\section{National Party Positions on Abortion}

Voter perceptions of candidate and party abortion positions in 1976 and 1980 presidential elections suggest that abortion is a much greater source of polarization among white Democrats in the Democratic party than for white Republicans in the Republican party (Bolce, 1988, p. 827). At the national level, abortion played only a minor role in the 1984 presidential election and congressional elections, affecting only a minority of voters (Granberg, 1987, p. 62), but as abortion policy is fought out on state terrain, the importance assigned to the issue in the minds of the voters could change.

In 1988, the two national parties were diametrically at odds on the abortion controversy. The 1988 Democratic national platform guaranteed the right of reproductive freedom regardless of the woman's ability to pay for an abortion, whereas the Republican national platform stated that the unborn child has a right to life which may not be infringed upon.

\section{Hypotheses and Data}

States are used as the unit of analysis to examine abortion policy here. After the Supreme Court's ruling in Webster v. Reproductive Health Services (1989), the battleground over abortion rights 
shifted to the state legislatures. By upholding the constitutionality of a Missouri law that restricted publicly funded abortions and required doctors to perform viability tests on fetuses that are twenty weeks old, the Supreme Court significantly modified Roe v. Wade (1973).

\section{Dependent Variables on State Restrictiveness}

We will examine indicators of previous and likely future state restrictiveness toward abortion policies, using three indices of state restrictiveness toward abortion as the dependent variable including the pre-Roe v. Wade index (as representative of the 1972 liberal era), the pre-Webster index (representing the interstices between Roe and Webster) and the post-Webster index (as representative of the cumulative effects of the 1980s on abortion restrictiveness).

\section{Pre-Roe v. Wade Index}

The pre-Roe index of state restrictiveness uses three categories, ranging from $1=$ most restrictive to $3=$ least restrictive, to summarize the abortion restrictions enacted in each state before 1972. It is based on data from all fifty states collected by the American Civil Liberties Union (ACLU). States where abortion was totally illegal or permitted only to save the life of the mother were considered the most restrictive. Those that permitted abortion for other purposes, such as fetal deformity, rape, or incest, or which imposed a lengthy state residency requirement, were recorded as moderate. Those that permitted abortion to protect the physical or mental health of the mother were considered to be most supportive of abortion rights and were coded least restrictive (Davis, 1985, pp. 254-257).

\section{Pre-Webster Index}

The Pre-Webster index delineates the restrictions placed on abortion in each state that existed after Roe v. Wade and immediately prior to the Webster decision. Numerous restrictions were reported in this index compiled by the Alan Guttmacher Institute.(1) Using the status of abortion laws during this time period, we classify state restrictiveness toward abortion in the following way: (a) states with two or more legislative restrictions on obtaining abortions were labeled most restrictive; (b) states with only one restriction on abortion access were recorded as moderate; and (c) states with no restrictions on access to abortion were considered to be in the least restrictive category.

\section{Post-Webster Index}


The post-Webster 1989 index measures on a state-by-state basis the likelihood that state legislatures will move toward placing greater restrictions on abortions given the status of their abortion legislation in 1988. This index was drawn from a survey which counted 19 states where new restrictions on abortion seemed likely to pass, 9 states where abortion rights appeared safe, and 22 states which were considered battlegrounds. It also ranges from one to three, with one labeling a state as most likely to restrict and three labeling a state as least likely to restrict access to abortions (Martz, McKillop, Foote, \& Padgett, 1989, p. 21).

When the pre-Webster and post-Webster indices were correlated, a significant relationship was found $(\mathrm{p}=.002)$, with a Pearson's $\mathrm{R}$ of .50 . This indicates that the two indices are measuring different aspects of abortion restrictiveness on a state-by-state basis. Post-Webster restrictions do not necessarily follow closely the same pattern as pre-Webster restrictions.

For the purposes of bivariate analysis, examining the relationship of single independent variables to abortion restrictiveness, the three-category indices of abortion restrictiveness were used. For multivariate logistic regression, a dichotomous measure was constructed where the middle category was added to the least restrictive category to produce a dichotomy between those states that were very restrictive toward abortion and all other states. By isolating the slates that are most likely to be restrictive and comparing them to the moderate and less restrictive states, it is possible to focus on those states that would be most likely to restrict womens' rights in the area of abortion.

For methodological and theoretical reasons, we examined the most restrictive states versus all other states by constructing a dichotomous measure where the middle "moderately restrictive" category of our initial three categories was added to the least restrictive category.

Methodologically, this provided a more even balance between restrictiveness and nonrestrictiveness (29 highly restrictive versus 21 less restrictive in the pre-Roe era; 15 versus 35 in the pre-Webster era; and 19 versus 31 in the post-Webster era) than alternative approaches to combining categories.

Substantively, contrasting highly restrictive states to all others better predicts the indicators in those states most likely to restrict abortion rights in the post-Webster era. Pro-choice groups and pro-life groups will also be more likely to focus their energies in the states likely to be highly restrictive. We are primarily concerned, then, in our multivariate analyses, with predicting those states most likely to severely restrict women's access to abortion, rather than predicting gradations of availability in more moderate states.

We expect to find the greatest impact of state-level independent variables on the pre-Roe and post-Webster indices which measure abortion restrictiveness in periods where states had greater policy flexibility. During the interstices between the Roe and Webster decisions, state flexibility in setting abortion restrictiveness as measured by the pre-Webster index was constrained by the federally mandated Roe decision. Thus, our state-level independent variables are not as likely to be correlated with abortion restrictiveness during the pre-Webster time period. 


\section{Independent Variables}

We use both political and socioeconomic variables as indicators of state abortion policy. ADA scores were collected from The Almanac of American Politics. Demographic and partisanship data were derived from the U.S. Statistical Abstract. Data on conservative religious denominations was collected from U.S. Census data and The Yearbook of American Churches (1985). If political variables are more important in each time period, cycle theory is supported. If socioeconomic variables are more important in this analysis of a bimodal issue, public opinion theory is supported.

When possible, 1972 data was used for the pre-Roe period and 1988 data for the pre- and postWebster periods, since abortion restrictiveness for the pre-Webster period reflected the status of state abortion laws as of 1988 immediately prior to the Webster decision. Religion variables, however, were from Census data, and were only available for 1970 and 1980, so these data, rather than 1972 and 1988, were used.

\section{Political Variables}

State political attitudes of liberalism/conservatism were measured as the average of each state's two U.S. Senators' ratings from Americans for Democratic Action (ADA) in 1972 and 1988. Additionally, partisanship was measured by: the party of each state's governor for 1972 and 1988; the proportion of Republicans in both state legislative houses for 1972 and 1988; and the proportion of Republicans in congressional state delegations for 1972 and 1988.

\section{Socioeconomic Variables}

Several religion variables were measured as the combined state population participating in selected conservative religious denominations and faiths (Catholic, American Baptist, Southern Baptist, United Methodist, Latter Day Saints, Church of God, and Assemblies of God), as a proportion of the total state population for 1970 and 1980. Other socioeconomic variables included in this analysis were: the proportion of Blacks and Hispanics by state for 1972 and 1988; urban-rural proportions within states for 1972 and 1988; and the per capita income of each state for 1972 and 1988. 


\section{Hypotheses}

In addition to testing cycle theory (political factors dominate issue evolution and policy outcomes) versus public opinion theory (for bimodal issues, socioeconomic factors dominate), hypotheses were developed concerning the importance of individual independent variables.

\section{The Hypothesized Impact of Political Factors on State Restrictiveness Towards Abortion}

If cycle theory is supported, political factors will be important determinants of abortion policy, and the impact of specific variables becomes relevant. The abortion controversy is increasingly framed as a partisan, ideological issue. Generally, findings support the notion that ideology is important in predicting attitudes toward abortion (Legge, 1983, p. 487).

To measure a state's proclivity toward liberalism or conservatism, the average of the state's two U.S. Senators' ratings from Americans for Democratic Action (ADA) for 1972 and 1988 are used. If, for example, a state elected two liberal Senators, this measure implies that the state has a more liberal political culture. If a state elects one Senator who receives low liberal ratings, this measure indicates that there is a more moderate political climate in which ideological divisions are less important. We hypothesize that state liberalism will be inversely related to restrictiveness on abortion.

If cycle theory is supported, political party will be related to state restrictiveness toward abortion. We expect states where Republicans dominated the governorship, lower and upper houses of the state legislatures, and the Congressional and Senatorial delegations to be more restrictive toward abortion. Further, we constructed a combined measure of Republicanism by state for both time periods of concern that averaged the proportion of Republicans in each of the above legislative delegations, excluding the governorship.

\section{The Hypothesized Impact of Socioeconomic Factors on State Restrictiveness towards Abortion}

If public opinion theory is supported, socioeconomic variables will be important determinants for abortion policy. Previous studies examining the relationship between demographics and abortion have focused primarily upon women who have received abortions, not upon states as units of public policy toward abortion. For example, earlier studies found that women receiving abortions are disproportionately young, white, unmarried, unlikely to have a college education, and residents of urban areas (Henshaw et. al., 1985; Henshaw et al., 1981; Henshaw \& O'Reilly, 1983; Sullivan et al., 1977; Tietze, 1977; Burnham, 1983; Prager, 1985). Among the socioeconomic factors examined for potential relationships with state restrictiveness toward abortion were the proportion of the population professing a socially conservative religion, the ethnic composition of the state, the proportion of state population that is urban, and state affluence measured by per capita income. 


\section{Religion}

A state with a high proportion of conservative religious adherents who eschew abortion may be more likely to pass new abortion restrictions than a state with religious adherents with more lenient views or a mixture of views on abortion. The conservative religions used in this analysis as a percent of the total state population were Catholic, American Baptist, Church of God, Southern Baptist, Assemblies of God, Latter Day Saints, and United Methodist. We hypothesize that the higher the proportion of state populations participating in religious faiths that sponsor restrictions on abortion, the greater the likelihood of abortion restrictiveness.

\section{Ethnicity}

In public opinion polls, both Blacks and Hispanics have had higher than average objections to abortion (Kelly, 1989, p. 85). Because of these attitudes, higher proportions of Blacks and Hispanics in state populations might increase the likelihood that state legislatures will impose additional restrictions on abortion rights. Data for 1982 from the General Social Survey of the National Opinion Research Center suggest that blacks are more likely to oppose abortion than whites.

At the same time, blacks are less likely than whites to regard the issue as one of the most significant (Scott \& Schuman, 1988, p. 788). Combs and Welch (1982, p. 510) also found that blacks were less supportive of abortion than whites. Still, findings are not conclusive on black attitudes toward abortion, and some research suggests that as blacks have gained increased access to abortion services and increasingly use them, their opposition to abortion has decreased (Baker et al., 1981, p. 89; Rodman et al., 1987, p. 152). The expansion in black usage of abortion increases uncertainty about the impact upon abortion policy of the presence of a substantial proportion of blacks in the state population, so the linkage between ethnicity and policy at the state level warrants further examination.

Hispanics are predominantly Catholic, a factor that might contribute to Hispanic opposition to abortion. Further, Hispanic culture is male centered, and in the past, a large number of children have been viewed as proof of male virility. These cultural aspects may cause the proportion of Hispanics within a state to be negatively related to pro-abortion policies.

\section{Rural Composition}

State composition, and in particular the proportion of state population living in rural areas, may affect citizen attitudes and orientations. Smaller communities tend to be more homogeneous whereas larger communities tend to be more heterogeneous. Larger, more urban communities are more likely to attract a wide variety of professionals, thus enhancing diversity. Various studies have shown that the more urban the community, the more liberal orientations it will exhibit (Key, 1967, pp. 111-112). This liberalization may occur in newer suburbanized areas as well as 
in central cities as a result of diversity in both. Diversity may enhance pro-abortion attitudes. Rural areas, however, are less likely to be diverse, and this lack of diversity may enhance antiabortion attitudes.

In the literature that examines individual American state public policy outcomes and what produces varying outcomes, state heterogeneity has been hypothesized as affecting the policies state governments adopt (Rae \& Taylor, 1970, pp. 7-8). The more diverse a state is, the more diverse demands its government will have to address. Sullivan (1973, p. 78) found a positive correlation between diversity and protection of minority rights. Studies also indicate that women who obtain abortions are predominantly metropolitan residents and are twice as likely to seek and obtain abortions as nonmetropolitan women (Powell-Griner \& Trent, 1987, p. 559). To the degree that greater urbanization increases heterogeneity and prevents the rise of majority tyranny by making the formation of a majority more difficult, it may be more difficult to pass additional restrictions on abortion rights in states with proportionately larger urban populations and proportionately smaller rural populations.

\section{Per Capita Income}

Various studies show that poor women are more likely to rely upon abortion than affluent women. One study found that women with a family income below $\$ 11,000$ are twice as likely as other women to have abortions. Other findings show that 77 percent, who are barely under or barely above the official poverty line, obtained abortions because they felt they could not afford to have a child (Kelly, 1989, p. 85). Yet poor women rarely have the necessary political clout to affect state legislatures (Piven \& Cloward, 1977, 1985).

Further, greater affluence overall may produce more liberal politics and more liberal stances toward abortion. Greater affluence is also correlated with a lower proportion of the population living in rural areas and greater urbanization, factors we expect to be positively related toward pro-abortion policies. Thus, we hypothesize here that higher levels of per capita income will be negatively related to state restrictiveness toward abortion.

\section{Findings}

\section{Bivariate Analysis of Political Variables}

Contingency table analysis allowed examination of the dependent variable with three categories and separate scrutiny of each independent variable's linkage to abortion restrictiveness. To construct nominal independent variables for the contingency table analysis, the midpoint 
employed was either the midpoint of the theoretical range, for the political ideological variables which had a fixed range from 0 to 100 , or the mean. Table 1 reports the chi-squares between state restrictiveness toward abortion and political and socioeconomic independent variables.

\section{TABULAR DATA OMITTED}

The bivariate analyses provide mixed support for both cycle and public opinion theories. Political variables generally were not significantly linked to abortion restrictiveness during the pre-Webster era, a period when abortion policy was set by the Supreme Court rather than by partisan state politics. For the pre-Roe period, the percent of the Congressional delegation that was Republican and the overall average proportion of representation that was Republican at both the state and congressional level is significantly linked to abortion restrictiveness. For the postWebster period, both ADA and average Republican representation are linked to abortion restrictiveness. These findings provide weak to moderate support for cycle theory, since political variables measuring the partisanship and orientation of elites are moderately linked to abortion restrictiveness.

The relationship between proportion of Republicans in the congressional delegation in pre-Roe era and state restrictiveness was nonlinear. States with a relatively high proportion of Republicans were more likely to be in both the most restrictive and the least restrictive categories toward abortion than were states with a low proportion of Republicans. Seventy percent of all states with a high percentage of Republicans were in the most restrictive category for abortion, compared to only $48 \%$ of states with a low percentage of Republicans. States with a low percentage of Republicans were more likely (44\%) than states with a high percentage of Republicans (12\%) to fall in the moderate category.

One explanation for this curvilinear relationship between state restrictiveness and Republican presence is that in states with a relatively high proportion of Republicans, Republican pro-life stances galvanized pro-choice forces, so that policies were either very restrictive, reflecting a Republican pro-life victory, or very liberal, reflecting a Democratic pro-choice victory. An alternative explanation for the simultaneous occurrence of a high incidence of Republicans in states with unrestrictive policies toward abortion is that one subgroup within the Republican party is more tolerant and moderate on questions of personal freedom. In a recent Times-Mirror survey used to develop a new typology of the American electorate, Ornstein, Kohut, and McCarthy (1988) found that Enterprise Republicans, a group that constituted $10 \%$ of the adult population and $16 \%$ of the likely electorate, opposed more restrictions on abortion.

Examining the linkage between abortion restrictiveness and ADA ratings for the post-Webster period, 53\% of states with low ADA ratings are in the most restrictive category, compared to $15 \%$ of high ADA states. Sixty percent of high ADA states are in the moderate restrictive category, compared to $33 \%$ of low ADA states. Twenty-five $\%$ of the states with high ADA ratings are in the least restrictive category, compared to $13 \%$ of low ADA states. This indicates that high ADA scores are generally associated with moderate or few restrictions on abortion, while low ADA scores are associated with greater restrictiveness. 


\section{Bivariate Analyses of Socioeconomic Variables}

The public opinion theory of issue evolution also receives partial support from the bivariate analyses. Two of the socioeconomic variables in the pre-Roe era were significantly related to the three-category measure of abortion restrictiveness--the percentage of Hispanics within the state and per capita income. For percentage of Hispanics, the relationship is not in the hypothesized direction. Rather, states with a relatively high percentage of Hispanics were more likely to have liberal abortion policies than states with a relatively low percentage of Hispanics. The percentage of blacks within a state, however, was not related to abortion restrictiveness in this time period, nor was the percent of the total population that adheres to a more conservative religion.

Per capita income was significantly related to abortion restrictiveness during the pre-Roe era in the hypothesized manner, so that high income states were more likely to assume liberal abortion policies than were low income states. While $70 \%$ of the low income states were in the most restrictive category toward abortion, only $39 \%$ of high income states assumed the most restrictive policies toward abortion. Only $3 \%$ of the low income states assumed liberal abortion policies, while $28 \%$ of the high income states did so. Plainly, affluence was strongly related with liberalism toward abortion.

Only one socioeconomic variable, per capita income, is a significant predictor of abortion restrictiveness for the post-Webster period. The nature of the relationship between per capita income and state restrictiveness toward abortion is the same as in the pre-Roe era, so that the more affluent the state, the greater the likelihood of supporting liberal policies toward abortion. Whereas $61 \%$ of low income states were predicted to assume restrictive positions toward abortion, only $19 \%$ of high income states were expected to do so. While only $14 \%$ of low income states were predicted to continue the liberal policies initiated nationwide by Roe v. Wade, $24 \%$ of high income states were expected to continue liberal policies. Neither the proportion of rural populations by state, the proportion of conservative religious adherents, nor black/Hispanic proportions by state appear to be significantly related to expectations of state policy restrictiveness.

\section{Multivariate Logistic Regression}

Logistic regression was employed to develop multivariate models that examined the simultaneous impact of several state indicators on the dichotomous measure of state restrictiveness. For logistic analysis, interval measures of the independent variables were used as predictors of the dichotomous measure of the dependent variable. Some scholars contend that an implied underlying continuum is sufficient for a dependent variable to be used in ordinary least squares regression. We ran OLS runs identical to the logistic regression runs reported here and found similar results. Since logistic regression is technically correct, however, only those results are reported here. 
Table 2 reports logistic regressions for the dichotomous measure of abortion restrictiveness for pre-Roe, pre-Webster, and post-Webster indices. The dependent variable in our logistic models compared states that were most likely to be restrictive with all others. From a policy viewpoint, states that deny women abortion totally or TABULAR DATA OMITTED TABULAR DATA OMITTED except under extreme hardship create the greatest threat to the reproductive freedom of women. We were primarily interested in predicting these threats.

In each run, logically grouped sets of independent variables are tested. Bivariate Pearson's R correlations between the independent variables used in the logistic runs reveal that multicollinearity may not be a problem since no correlation among independent variables is above 0.8 , and most correlations between independent variables are well below 0.5 . For each model tested, the model chi-square as a measure of goodness of fit as well as its associated probability is reported to indicate model significance.

As an additional indication of the power of each model, an R-Square for each model was approximated by dividing the model chi-square for the $-2 \log$ likelihood ratio by the $-2 \log$ likelihood for the model containing the intercept only. This approximates an R-Square in traditional OLS, but differs from it in that the dependent variable in logistics regression is not the straightforward measure of the dependent variable, but rather the $\log ! \mathrm{Pi} /\left(\text { !-P.sub. } \mathrm{i}^{\wedge}\right)^{\wedge}$ (Aldrich and Nelson, 1984).

We examine model chi-squares, significance levels, and approximated R-squares to ascertain the relative weight of clusters of variables so as to test the relevance of cycle and public opinion theory for abortion policies. However, we also report independent variable coefficients and their associated chi-square probabilities within each model.

\section{Multivariate Analysis of Political Variables}

Two different models with political variables alone were tested. The first set of political models used state partisanship variables (proportion of Republicans in the governorship, each house of the state legislature, and each house in Congress). None of these models was significant for any of the three periods examined.

A second set of political models used an average of the five variables measuring proportion of Republican representation in different settings, and ADA as a measure of liberalism. This political model was significant only for the post-Webster period, with a model chi-square of 17.00, a significance level of .0002, and an approximate R-square of .26.

Political variables were not significant in the more liberal pre-Roe era of 1972 or during the preWebster period when state politicians were constrained by the Roe decision, indicating that the cycle theory is less important for explaining abortion policy formation. On the other hand, during the post-Webster era, political factors were significantly linked to abortion restrictiveness, illustrating how the dominance of conservatism may increase party differences and heighten partisan conflict over a controversial issue like abortion. 


\section{Multivariate Analysis of Socioeconomic Variables}

Two sets of models employing socioeconomic indicators tested the importance of public opinion theory in which socioeconomic variables were predicted to be significant in policy formation. In the first set, state measures of percent of the population adhering to various conservative religious faiths were used. This model was significant only for the post-Webster period. The model for the post-Webster period had a model chi-square of 23.27, a significance level of .0007, and an approximate R-square of .44. These results support our hypothesis that conservative religious participation is an indicator of abortion restrictiveness but only in the most recent period.

When participation in conservative religions was considered as a single variable and combined with other socioeconomic indicators (per capita income, percent black, percent hispanic, percent rural population), the socioeconomic models testing public opinion theory were significant in all three periods.

Approximated R-squares ranged from .20 in the pre-Roe period to .33 in the post-Webster period. The higher approximate R-square for the post-Webster period indicates that socioeconomic variables were more important in the conservative era. Thus public opinion theory is somewhat more useful for explaining abortion restrictiveness during periods of conservatism.

\section{Political and Socioeconomic Variables}

The last set of logistic models in Table 2 combines political and socioeconomic variables. This model combining political and socioeconomic variables was also significant in all periods, with approximate R-squares ranging from .26 in the pre-Roe period and .25 in the pre-Webster period to .47 in the post-Webster period. The only variable significant in all three models is a socioeconomic one: per capita income. Percent black is also significant in the pre-Roe period and ADA in the post-Webster period. The significant and consistent role of a socioeconomic variable in all three periods, and the fact that only one political variable was significant in one period, lends further credence to the dominance of public opinion theory over cycle theory.

\section{Conclusions}

This paper compared and contrasted the potency of political indicators with socioeconomic indicators in explaining state restrictiveness toward abortion. The two theories of policy formation offer different outlooks on how the formulation of abortion policy responds to dominant periods of liberalism and conservatism (cycle theory) and to the framing of the issue as bimodal (public opinion theory). Some support is found for both cycle and public opinion theory, 
especially in the post-Webster period. Support for public opinion theory is more consistent than that for cycle theory, however.

Political variables were more important in the conservative post- Webster era than in either the liberal pre-Roe era, or the pre-Webster period when the Supreme Court set policy. Conservative dominance of an era may heighten party differences when the preferred liberal policy position is the status quo, as was the case in the post-Roe periods. Religion was more important in the conservative era than in the liberal era, indicating that conservatism may also sharpen religious and regional differences. Per capita income impacted on likelihood of abortion restrictiveness no matter what the ideological character of the era. Further, the fact that more affluent states adopt liberal policies toward abortion indicates that anti-abortionists would be most effective in states with lower per capita incomes.

In conclusion, we explained about one-fourth of the variance in the pre-Roe period and approximately one-half in the post-Webster period. All political variables combined explained one-fourth of the variance in the post-Webster era. All socioeconomic variables combined explained approximately one-fourth of the variance in the pre-Roe era and almost one-half of the variance in the post-Webster period. As expected, the pre-Webster index did not correlate as highly with our state level independent variables since states were constrained by a federal level policy directive--Roe v. Wade. The rest of the variance, not accounted for in this analysis, may be explained by the power of interest groups, individual state cultural differences, and institutional processes and constraints.

Ruth Ann Strickland is an Assistant Professor in the Department of Political Science and Criminal Justice at Appalachian State University.

Marcia Lynn Whicker is a Professor in the Public Administration Department at Rutgers University--Newark.

\section{Notes}

1 The restrictions recorded in this index include: protection of the fetus in the Preamble of the state's Constitution ( 9 states); specification of a degree of care required toward the fetus (6 states); viability testing (2 states); viability of fetus assumed at a certain number of weeks (13 states); prohibition of abortion counseling (4 states); prohibition of public employee involvement in abortion-related activities ( 2 states); prohibition of the use of public facilities for abortion services (4 states); restrictions on public funding for abortions (37 states); and trigger laws that would automatically make abortion illegal (5 states).

2 Since the primary dependent variable in logistic regression is not the variable itself, but the log of the likelihood of the odds ratio, the interpretation of individual coefficients for more than the significance of the linkage of the independent variable to the dependent variable is suspect. 
APPENDIX I. STATE SCORES ON ABORTION RESTRICTIVENESS

\begin{tabular}{|c|c|c|c|}
\hline $\mathrm{ST}$ & Pre-Roe & Pre-Web & Post-Web \\
\hline $\mathrm{AL}$ & 2 & 2 & 1 \\
\hline$A K$ & 2 & 3 & 3 \\
\hline $\mathrm{AZ}$ & 1 & 2 & 2 \\
\hline$A R$ & 2 & 1 & 1 \\
\hline $\mathrm{CA}$ & 3 & 3 & 3 \\
\hline $\mathrm{CO}$ & 3 & 2 & 2 \\
\hline CT & 3 & 3 & 2 \\
\hline $\mathrm{DE}$ & 2 & 2 & 2 \\
\hline FL & 1 & 2 & 1 \\
\hline GA & 2 & 2 & 1 \\
\hline $\mathrm{HI}$ & 2 & 3 & 3 \\
\hline ID & 1 & 1 & 1 \\
\hline IL & 1 & 1 & 2 \\
\hline IN & 1 & 1 & 1 \\
\hline IA & 1 & 2 & 3 \\
\hline KS & 3 & 2 & 2 \\
\hline KY & 1 & 1 & 1 \\
\hline LA & 1 & 1 & 1 \\
\hline $\mathrm{ME}$ & 1 & 2 & 3 \\
\hline MD & 3 & 3 & 2 \\
\hline MA & 2 & 2 & 2 \\
\hline MI & 2 & 2 & 2 \\
\hline MN & 1 & 1 & 1 \\
\hline MS & 2 & 2 & 1 \\
\hline MO & 2 & 2 & 1 \\
\hline MT & 1 & 2 & 2 \\
\hline $\mathrm{NE}$ & 1 & 1 & 1 \\
\hline NV & 1 & 1 & 2 \\
\hline $\mathrm{NH}$ & 1 & 2 & 2 \\
\hline NJ & 1 & 3 & 2 \\
\hline NM & 3 & 2 & 3 \\
\hline NY & 2 & 2 & 3 \\
\hline $\mathrm{NC}$ & 2 & 2 & 2 \\
\hline ND & 1 & 1 & 2 \\
\hline $\mathrm{OH}$ & 1 & 2 & 2 \\
\hline OK & 1 & 1 & 1 \\
\hline OR & 2 & 3 & 2 \\
\hline $\mathrm{PA}$ & 1 & 1 & 1 \\
\hline RI & 1 & 2 & 2 \\
\hline $\mathrm{SC}$ & 2 & 2 & 1 \\
\hline SD & 2 & 1 & 2 \\
\hline TN & 2 & 1 & 2 \\
\hline $\mathrm{TX}$ & 1 & 2 & 1 \\
\hline UT & 1 & 1 & 1 \\
\hline VT & 1 & 3 & 3 \\
\hline VA & 1 & 2 & 2 \\
\hline WA & 2 & 3 & 3 \\
\hline WV & 1 & 3 & 1 \\
\hline WI & 1 & 2 & 2 \\
\hline WY & 1 & 2 & 1 \\
\hline
\end{tabular}




\section{References}

Alan Guttmacher Institute (1989). Status of abortion laws. Congressional Quarterly Almanac, 45, 298.

Aldrich, J. R., \& Nelson, F. D. (1984). Linear probability, logit, and probit models. Beverly Hills, CA: Sage Publications.

Baker, R. K., Epstein, L. K., \& Forth, R. D. (1981). Matters of life and death: Social, political, religious correlates of attitudes on abortion. American Politics Quarterly, 9, 89-102.

Barone, M., Ujfusa, G., \& Matthews, D. (1972). Almanac of American politics. Boston, MA: Gambit.

Barone, M., \& Ujfusa, G. (1988). Almanac of American politics. Washington, DC: National Journal, Inc.

Bolce, L. (1988). Abortion and presidential elections: The impact of public perceptions of party and candidate positions. Presidential Studies Quarterly, 18, 815-829.

Burham, D. (1983). Induced terminations of pregnancy: Reporting states, 1980. Monthly Vital Statistics Report 32 (8: suppl.). (DHHS Publication No. PHS 84-1120). Washington, DC: U.S. Government Printing Office.

Callahan, J. C. (1986, April 11). The fetus and fundamental rights. Commonweal, 13, 203-209.

Combs, M. W., \& Welch, S. (1982). Blacks, whites and attitudes towards abortion. Public Opinion Quarterly, 46, 510-520.

Countdown: The wars between the states. (1989, July 17). Newsweek, p. 24.

Davis, N. J. (1985). From crime to choice: The transformation of abortion in America. Westport, CT: Greenwood Press.

Dawson, R. (1973). Public opinion in contemporary disarray. New York: Harper and Row.

Downs, A. (1957). An economic theory of democracy. New York: Harper and Row.

Edsall, T. B. (1989, July 17-23). Abortion: From rhetoric to action. Washington Post National Weekly, pp. 6, 10-11. 
Elving, R. D. (1990, January 26). Abortion: Politicians' nightmare. Editorial Research Reports, 1, 50-62.

Feldman, D. (1987). Ethical analysis in public policymaking. Policy Studies Journal, 15, 441459.

Fried, A. (1988). Abortion politics as symbolic politics: An investigation into belief systems. Social Science Quarterly, 69, 137-154.

Granberg, D. (1981a, July/August). The abortion activists. Family Planning Perspectives, 13, 157-163.

Granberg, D. (1981b). The abortion controversy: An overview. Humanist, 41, 28-38.

Granberg, D. (1987, March/April). The abortion issue in the 1984 elections. Family Planning Perspectives, 19, 59-62.

Henshaw, S. K. (1987, March/April). Abortion services in the United States, 1984 and 1985. Family Planning Perspectives, 19, 63-70.

Henshaw, S. K., Binkin, N. J., Blaine, E., \& Smith, J. C. (1985). A portrait of American women who obtain abortions. Family Planning Perspectives, 17, 90-96.

Henshaw, S. K., Forrest, J. D., Sullivan, E., \& Tietze, C. (1981). Abortions in the U.S., 19781979. Family Planning Perspectives, 13, 6-18.

Henshaw, S. K., \& O'Reilly, K. (1983). Characteristics of abortion patients in the U.S., 1979 and 1980. Family Planning Perspectives, 15, 5-16.

Hertel, B. R., \& Hughes, M. (1987). Religious affiliation, attendance, and support for 'profamily' issues in the United States. Social Forces, 65, 858-882.

Kelly, J. R. (1989, February 4). Catholic abortion rates and the abortion controversy. America, $160,82-85$.

Key, V. O. (1967). Public opinion and American democracy. New York: Alfred A. Knopf.

Legge, Jr., J. S. (1983). The determinants of attitudes toward abortion in the American electorate. Western Political Quarterly, 36, 479-490.

Martz, L., McKillop, P., Foote, J., \& Padgettt, T. (1989, July 17). The new political rules. Newsweek, 114, 21.

Meehan, Mary. (1981). Catholic liberals and abortion. Commonweal, 108, 650-654. 
Phillips, K. (1990). The politics of rich and poor: Wealth and the American electorate in the Reagan aftermath. New York: Random House.

Piven, F. F., \& Cloward, R. A. (1977). Poor people's movements: Why they succeed, how they fail. New York: Vintage Books.

Piven, F. F., \& Cloward, R. A. (1985). The new class war: Reagan's attack on the welfare state and its consequences (rev. ed.). New York: Vintage Books.

Powell-Griner, E., \& Trent, K. (1987). Sociodemographic determinants of abortion in the United States. Demography, 24, 553-561.

Omstein. N., Kohut, A., \& McCarthy, L. (1988). The people, the press, and politics: The TimesMirror study of the American electorate, Reading. MA: Addison-Wesley Publishing Co.

Petchesky, R. P. (1990). Abortion and woman's choice: The state, sexuality, and reproductive freedom (rev. ed). Boston, MA: Northeastern University Press.

Prager K. (1985). Induced terminations of pregnancy: Reporting states, 1981. Monthly Vital Statistics Report 34 (4; suppl. 2) (DHHS pub. no. PHS 85-1120). Washington, DC: U.S. Government Printing Office.

Rae, D. M., \& Taylor, M. (1970). The analysis of political cleavages. New Haven, Connecticut: Yale University Press.

Rodman, H., Sarvis, B., and Bonar, J. W. (1987). The abortion question. New York: Columbia University Press.

Schlesinger Jr., A.M. (1986). The cycles of American history. Boston: Houghton Mifflin.

Scott, J., \& Schuman, H. (1988). Attitude strength and social action in the abortion dispute. American Sociological Review, 53, 785-793.

Sheeran, P.J. (1987). Women, society, the state, and abortion: A structuralist analysis. New York: Praeger Publishers.

Strickland, R.A., \& Whicker, M.L. (1986). Banning abortion: An analysis of Senate votes on a bimodal issue. Women and Politics, 6, 41-56.

Sullivan, E., Tietze, C., \& Dryfoos, J.G. (1977). Legal abortion in the U.S., 1975-1976. Family Planning Perspectives, 9, 116-129.

Sullivan, J. L. (1973). Political correlates of social, economic and religious diversity in the American states. Journal of Politics, 35, 70-84. 
Tatalovich, R., \& Daynes, B. W. (1981, November 20). The trauma of abortion politics. Commonweal, 108, 644-649.

Tedrow, L. M., \& Mahoney, E. R. (1979). Trends in attitudes toward abortion: 1972-1976. Public Opinion Quarterly, 43, 181-189.

Tietze, C. 1977. Legal abortion in the U.S.: Rates and ratios by race and age., 1972-1974. Family Planning Perspectives, 9, 12-15.

Traugott, M.W., \& Vinoskis, M. A. (1980, September/October). Abortion and the 1978 congressional elections. Family Planning Perspectives, 12, 238-246.

Webster v. Reproductive Health Services, 109 S.Ct. 3040 (1989).

Whicker, M.L., \& Kronenfeld, J.J. (1986). Sex role changes: Technology, politics and policy. New York: Praeger Publishers.

Woodworth, K. \& Cohen, A. (1989, July 24). Abortion and the churches. Newsweek, 114, 45-46.

U.S. Department of Commerce, Bureau of the Census. (1972). Statistical abstract of the United States, 1972. Washington, DC: U.S. Government Printing Office.

U.S. Department of Commerce, Bureau of the Census. (1988). Statistical abstract of the United States, 1988. Washington, DC: U.S. Government Printing Office.

Yearbook of American Churches (1985) 